\title{
Editorial
}

\section{Advances in Interfaces}

This special issue is entitled "Advances in Interfaces". The authors in this special issue consider a number of issues associated with interface design. Some of these studies have worked with desktop displays that are capable of true three dimensional displays (Duenser and Mancero; Phillips and Carr), another addresses night vision systems (Stuart and Hughes). These authors consider factors influencing the usability of displays. The authors consider how depth (Duenser and Mancero) or colour (Duenser and Mancero; Stuart and Hughes) can make key features of the display more salient. One paper looks at the implication of three dimensional displays for cursor positioning (Phillips and Carr).

Even though there has been a trend towards devices with convergent capabilities, papers suggest that the context (Kantowitz and Nathan-Roberts) and the location of device and user (Hoffmann) will influence how the interface is used. These papers identify themes that extend to attempts to improve mobile phone interfaces.

As computing devices, mobile phones have sacrificed keyboards and screen size in favour of portability. Hence web enabled mobile phones have problems when entering text to login to accounts (Poet and Renaud) send messages (Ancona and Quercini) and access websites (Isomursu). These papers seek to reduce the need for text based input in a variety of ways. Poet and Renaud have been developing pictures as alternate password systems, reducing the need for keyboards and spelling. Ancona and Quercini use context relevant dictionaries to anticipate a word from reduced character input (or use handwriting recognition instead). Isomursu turns the world into a menu by augmenting reality using machine readable tags that contain the links to websites. Another solution is to eliminate the need to enter websites by making recommendations to the user. A final paper considers the circumstances under which potential consumers may utilise the advice offered by recommenders (OHare, Phillips, and Moss). It appears that the level of ability and degree of risk may influence the user's willingness to use computer recommendations.

Will these innovations in this special issue advance interface design? Possibly, but if they do, the reliability of the device and the appropriateness of the support it supplies [1] will continue to be important. Indeed there are already intimations that computing devices should mind their own business (or mind their manners) [2]. With the growing pervasiveness of computing devices I hope that these well-intentioned future interfaces will support the user's interests, and not be overwhelmed by advertising and graffiti.

\section{REFERENCES}

[1] Parasuraman R, Riley V. Humans and automation: use, misuse, disuse, abuse. Hum Factors 1997; 39: 230-53.

[2] Whitworth B. Polite computing. Behav Inf Techol 2005; 24: 353-63.

J.G. Phillips

(Guest Editor)

School of Psychology

Psychiatry, \& Psychological Medicine

Monash University

Australia

E-mail: jim.phillips@med.monash.edu.au

(C) J.G. Phillips; Licensee Bentham Open.

This is an open access article licensed under the terms of the Creative Commons Attribution Non-Commercial License (http: //creativecommons.org/licenses/bync/3.0/) which permits unrestricted, non-commercial use, distribution and reproduction in any medium, provided the work is properly cited. 